University of Nebraska - Lincoln

DigitalCommons@University of Nebraska - Lincoln

\title{
Fabrication of High Aspect Ratio Metal Nanotips by Nanosecond Pulse Laser Melting
}

\author{
Bo Cui \\ Princeton University \\ Lin Wu \\ University of Nebraska-Lincoln, Iwu2@unl.edu \\ Stephen Y. Chou \\ Princeton University
}

Follow this and additional works at: https://digitalcommons.unl.edu/mechengfacpub

Part of the Mechanical Engineering Commons

Cui, Bo; Wu, Lin; and Chou, Stephen Y., "Fabrication of High Aspect Ratio Metal Nanotips by Nanosecond Pulse Laser Melting" (2008). Mechanical \& Materials Engineering Faculty Publications. 20. https://digitalcommons.unl.edu/mechengfacpub/20

This Article is brought to you for free and open access by the Mechanical \& Materials Engineering, Department of at DigitalCommons@University of Nebraska - Lincoln. It has been accepted for inclusion in Mechanical \& Materials Engineering Faculty Publications by an authorized administrator of DigitalCommons@University of Nebraska Lincoln. 


\title{
Fabrication of high aspect ratio metal nanotips by nanosecond pulse laser melting
}

\author{
Bo Cui, ${ }^{1} \mathrm{Lin} \mathrm{Wu}^{2}$ and Stephen Y. Chou ${ }^{1}$ \\ 1 NanoStructure Laboratory, Department of Electrical Engineering, Princeton University, \\ Princeton, NJ 08544, USA \\ 2 Department of Mechanical Engineering, University of Nebraska-Lincoln, Lincoln, NE \\ 68588, USA
}

Corresponding author - S. Y. Chou, chou@princeton.edu

\begin{abstract}
The authors have developed an approach to fabricate sharp and high aspect ratio metal tips using nanosecond pulse laser melting. A quartz wafer covered with a thin chromium $(\mathrm{Cr})$ film was placed on top of a second wafer with a sub-micrometer gap between them and the $\mathrm{Cr}$ film facing the second wafer. Then an excimer laser pulse (308 nm wavelength, $20 \mathrm{~ns}$ pulse duration) was shone from the back of the quartz wafer and melted the Cr film momentarily (several hundred nanoseconds). It is found that the molten $\mathrm{Cr}$ films can self-form discrete metal pillars connecting the two wafers. After separating the two wafers, nanotips were formed at the broken pillar necks. The sharpest tip achieved has an apex diameter $10 \mathrm{~nm}$ and height $180 \mathrm{~nm}$. The self-formation of Cr pillars between the two wafers was attributed to the attractive electrostatic force caused by the work function difference of two wafers that were in close proximity. This technique could be extended to other metals, and a periodic uniform tip array could be obtained by pre-patterning the metal into identical isolated mesas and precisely controlling the gap between the two wafers.
\end{abstract}

\section{Introduction}

Nanotips have many applications such as scanning probe microscopy (SPM) and vacuum microelectronic devices like field emission display (FED), where their performance is often limited by the tip. In SPM, a sharp tip with a small apex diameter leads to a high resolution, while a high aspect ratio is essential to image deep vertical structures without significant artifacts. In FED, the efficiency of electron emission is largely determined by the emitter material and its sharpness. Carbon nanotubes [1, 2] or nanocones [3] have been studied extensively for application as tips or emitters owing to their fine diameter and high aspect ratio. Tang et al. have synthesized AlN nanotips by chemical vapor deposition [4]. Silicon tips with low aspect ratio have been fabricated by isotropic wet [5] or dry etching [6], while that with high aspect ratio can be readily fabricated by highly anisotropic dry etching [7].

Metal is highly conductive and mechanically strong and robust, which are favorable properties for field emitters or scanning probes. Unfortunately, it is more challenging to fabricate metal tips on a wafer due to the difficulty in etching metals. A single metal tip can be routinely fabricated by focused ion beam milling [8] or electrochemical etching [9]. But for FED or high throughput nanolithography using SPM, tip arrays are essential, which are very difficult to fabricate by the previous two methods. Metal tip arrays with low aspect ratio were traditionally fabricated by the Spindt process, in which the metal is evaporated through apertures that become gradually closed by the evaporated material [10]. Similarly, although by a different mechanism, Au tips were formed by evaporation into porous alumina [11]. Alternatively, metal tips can be replicated by physical vapor deposition or electroplating into holes etched in silicon by $\mathrm{KOH}[12,13]$, laser-micromachined in glass [14], or created in $\mathrm{SiO}_{2}$ by repeated etching and deposition into pre-patterned holes [15].

Another possible way to pattern metal is by melting it using a pulsed laser. Previously, we have presented laser-assisted direct imprint (LADI) [16], nanoimprint lithography (LAN) [17], nanotransfer printing [18], and via hole filling [19]. In this work we demonstrate that sharp metal tips can be self- 


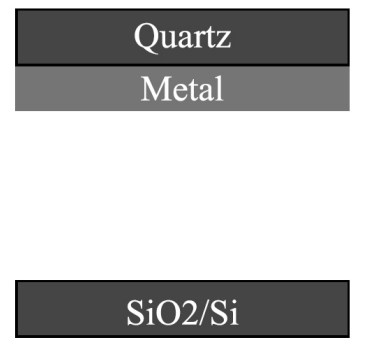

1. Wafer arrangement

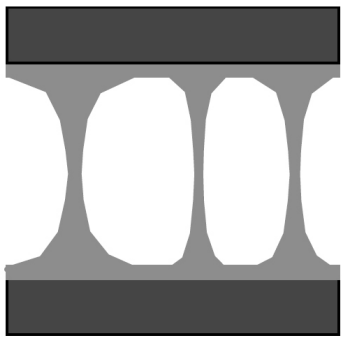

2. Irradiate by laser

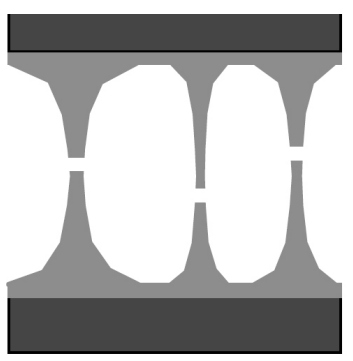

3. Solidify and separate

(a)

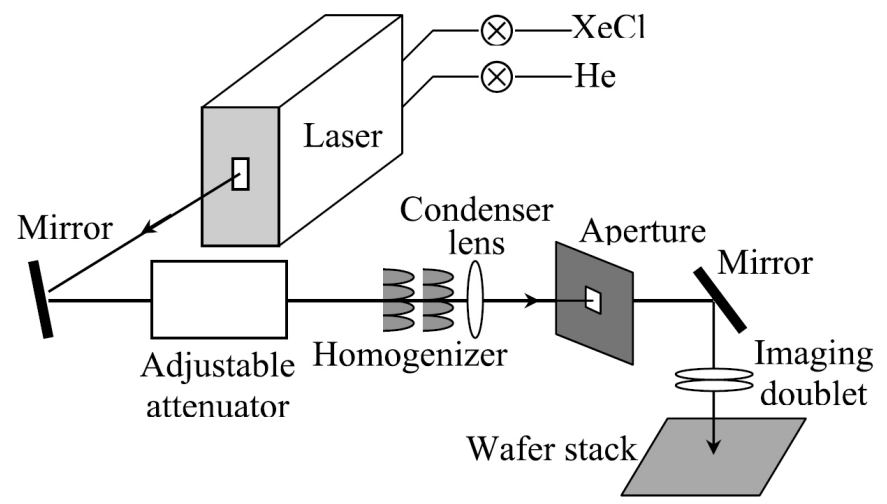

(b)

Figure 1. (a) Schematic laser-induced metal nanotip formation process; (b) schematic set-up of the excimer laser and optical components.

formed by simply melting momentarily ( $100 \mathrm{~ns})$ a metal film deposited on a wafer with a second wafer placed a gap (submicrometers) below. Unlike previous methods for metal tip fabrication, the current one is capable of producing high aspect ratio metal tip arrays.

\section{Experiments}

In our experiments (see Figure 1(a)), a metal film such as 25 $\mathrm{nm} \mathrm{Cr}$ was first evaporated on a transparent UV grade quartz wafer. Then a silicon wafer with $500 \mathrm{~nm}$ thermal oxide was placed below the $\mathrm{Cr}$ film with a gap formed by a spacer. Next, a single excimer laser pulse (fluence $0.4 \mathrm{~J} / \mathrm{cm}^{2}$ ) was shone through the quartz melting the metal film momentarily and causing it to transfer toward the lower wafer. The two wafers were separated after $\mathrm{Cr}$ solidification and examined by scanning electron microscopy (SEM).

An excimer laser was chosen because it has high photon energy (short wavelength) that allows for strong optical absorption in most metals, a short pulse length that minimizes substrate heating and damage, and relatively poor coherence (since an excimer laser's output is highly multimode and contains as many as $10^{5}$ transverse modes [20]) that diminishes interference effects.

We used an $\mathrm{XeCl}$ excimer laser from Lambda Physik (model no. COMPex 102) with $308 \mathrm{~nm}$ wavelength and $20 \mathrm{~ns}$ FWHM pulse duration (see Figure 1(b) for optical set-up). The maximum stable output energy is $160 \mathrm{~mJ} /$ pulse, which produces a fluence of $2.56 \mathrm{~J} / \mathrm{cm}^{2}$ and a light intensity of $130 \mathrm{MW} /$ $\mathrm{cm}^{2}$, for a focused spot size of $2.5 \times 2.5 \mathrm{~mm}^{2}$. This light intensity is high enough to cause vaporization and plasma formation in front of many metal targets, so it needs to be further attenuated by an attenuator that allows a transmission range of $10-90 \%$. The homogenizer and condenser lens are used to generate a mesa-shaped spatial intensity profile with much more uniform distribution. The spatial plane of this intensity profile is called the homogenized plane. A metal aperture is mounted at the homogenized plane to block off the edges of the beam and side lobes, resulting in a nearly flat top spatial intensity profile for the laser pulse. The spot size, here $2.5 \times 2.5 \mathrm{~mm}^{2}$, is determined by the separation between the imaging doublet and the substrate.

\section{Results}

For proof of concept, chromium was selected due to its excellent adhesion to silicon dioxide. After illumination by a pulse of fluence $0.4 \mathrm{~J} / \mathrm{cm}^{2}\left(20 \mathrm{MW} / \mathrm{cm}^{2}\right)$, Cr nanotips were found to form both on the $\mathrm{SiO}_{2} / \mathrm{Si}$ substrate (Figure 2(a)) and on the quartz wafer (Figure 2(b)) that was originally coated with a $25 \mathrm{~nm}$ thick $\mathrm{Cr}$ film by e-beam evaporation. The sharpest tip, shown in the inset in Figure 2(b), has an apex diameter of about $10 \mathrm{~nm}$ and height $180 \mathrm{~nm}$. The size, shape and location of the tips are random, but more regular tips are expected if the $\mathrm{Cr}$ is pre-patterned into identical isolated mesas. The tallest tip has a height of $500 \mathrm{~nm}$, suggesting the optimum gap for tip formation is $500-1000 \mathrm{~nm}$ if assuming the tip was broken at the mid-point (in the experiment the gap between the two 
wafers varied gradually depending on the distance from the spacer). The ends of most tips resemble a sharp cone (not flat), hence they should be broken by the tensile force due to surface tension and/or volume shrinkage upon solidification; while those with a flat end were broken by mechanical force when the two wafers were separated.

\section{Discussion}

The characteristic optical penetration depth (equal to $\lambda / 4 \pi k, k$ is the imaginary part of the refractive index) is $10 \mathrm{~nm}$ for $\mathrm{Cr}$ at $\lambda=308 \mathrm{~nm}$, leading to a transmission of $8 \%$ for $25 \mathrm{~nm} \mathrm{Cr}$. The reflectivity at the air $/ \mathrm{SiO}_{2}$ and $\mathrm{SiO}_{2} / \mathrm{Cr}$ interface is $3.8 \%$ and $40 \%$, respectively. Therefore, $53 \%$ laser energy $(0.21 \mathrm{~J} /$ $\mathrm{cm}^{2}$ ) was absorbed by the $\mathrm{Cr}$ film. As the quartz wafer is transparent, the laser energy is first absorbed by the $\mathrm{Cr}$ film and then transferred to the substrate to a characteristic depth of order $150 \mathrm{~nm}$ (equal to $\sqrt{ } D t_{\mathrm{p}^{\prime}} D$ is thermal diffusivity and $t_{\mathrm{p}}$ is pulse duration equal to $20 \mathrm{~ns}$ ) at the end of the pulse. The energy needed to heat $25 \mathrm{~nm}$ Cr film to its boiling point $(2945$ $\mathrm{K}$ ) and the latent heat of vaporization is $0.04 \mathrm{~J} / \mathrm{cm}^{2}$ and 0.10 $\mathrm{J} / \mathrm{cm}^{2}$, respectively [21], and the energy loss to the $\mathrm{SiO}_{2}$ substrate with the temperature at the top surface of $2945 \mathrm{~K}$ is estimated to be $0.12 \mathrm{~J} / \mathrm{cm}^{2}$ [22]. Thus laser energy of $\sim 0.16 \mathrm{~J} / \mathrm{cm}^{2}$, which is less than the actual absorbed energy of $0.21 \mathrm{~J} / \mathrm{cm}^{2}$, would be needed to heat the $\mathrm{Cr}$ film to its boiling point. Therefore, it is estimated that the temperature of the Cr film is at (or above, see below) its boiling point at the end of the laser pulse. As the typical plasma temperature is $\sim 10,000 \mathrm{~K}$, which is well above the boiling point of $\mathrm{Cr}$ and the laser energy the $\mathrm{Cr}$ vapor "sees" after strong (92\%) absorption by the Cr film is very low, there should not be plasma (substantially ionized vapor) formation inside the gap between the two wafers.

When the metal film coated on the quartz wafer is illuminated and consequently melted and vaporized by a laser beam, part of it is deposited onto the lower wafer through an evaporation and condensation process. To obtain an upper limit of evaporation rate, we assume that the evaporating molecules are immediately removed such that none returns to the surface. Then the net rate of evaporation $G$ is given by $G=0.058$ $p(M / T)^{1 / 2} \mathrm{~g} \mathrm{~cm}^{-2} \mathrm{~s}^{-1}$, where $p$ is the vapor pressure (Torr), $M$ is the molar mass $\left(\mathrm{g} \mathrm{mol}^{-1}\right)$ and $\mathrm{T}$ is temperature $(\mathrm{K})$ [23]. For $\mathrm{Cr}$ at its boiling point, $p=760$ Torr, $M=52 \mathrm{~g} \mathrm{~mol}^{-1}$ and $T=2945$ $\mathrm{K}$, leading to $G=5.9 \mathrm{~g} \mathrm{~cm}^{-2} \mathrm{~s}^{-1}$ or $0.009 \mathrm{~nm} / \mathrm{ns}$ (liquid $\mathrm{Cr}$ density $\rho=6.5 \mathrm{~g} / \mathrm{cm}^{3}$ ), which results in an evaporation of only 0.18 $\mathrm{nm} \mathrm{Cr}$ for $20 \mathrm{~ns}$. Therefore, rather than evaporating the $\mathrm{Cr}$, the "remaining" laser energy $\left(\sim 0.05 \mathrm{~J} / \mathrm{cm}^{2}\right)$ would further heat up the liquid $\mathrm{Cr}$ (and $\mathrm{SiO}_{2}$ substrate) beyond its boiling point by several hundred degrees that increases drastically the evaporation rate. Nonetheless, evaporation alone is unlikely to be able to account for the substantial mass transfer to the lower wafer; and the internal pressure owing to boiling of the metal or contaminants at the $\mathrm{SiO}_{2} / \mathrm{Cr}$ interface should also contribute significantly to, or even dominate, the mass transfer.

Since the melting temperature of quartz is only $1883 \mathrm{~K}$, a top $\mathrm{SiO}_{2}$ layer of order $100 \mathrm{~nm}$ on both wafers should have been melted by heat transfer. However, due to the six orders higher viscosity of molten $\mathrm{SiO}_{2}$ compared to that of chromium $\left(3.0 \times 10^{6} \mathrm{cP}\right.$ for $\mathrm{SiO}_{2}$ versus $3.7 \mathrm{cP}$ for $\mathrm{Cr}$ at $2673 \mathrm{~K}$ [22]), the flow of the molten $\mathrm{SiO}_{2}$ is negligible, leading to no apparent distortion of the two wafer surfaces.
The experimentally observed metal nanotip formation phenomenon can be explained in terms of an electrohydrodynamic instability process as shown in Figure 3. Briefly, the nanotip formation can be roughly divided into four stages: free charge build-up, mass transfer to the lower wafer upon laser illumination, liquid pillar formation due to electrostatic attraction, and solidification and breaking of the pillars.

Once the two wafers are brought close together, free charges are built up on both wafers due to the work function difference between $\mathrm{Cr}$ and $\mathrm{SiO}_{2}$, which results in a strong electric field of order $10^{5} \mathrm{~V} / \mathrm{cm}$ for a $500 \mathrm{~nm}$ gap. Interaction between electric field and polarized or free charges accumulated at the interface results in an electrostatic pressure. Electrostatic pressure gradient driven flow has been previously employed to self-assemble an initially flat layer of dielectric polymers coated on a substrate into micrometer-size pillars that bridge the substrate and a pre-patterned mold placed above [24-29]. Similarly, the attractive electrostatic force sets the two molten metal films into tension subject to infinitesimal disturbances, and interfacial ripples start to develop. The periodicity of the ripple that determines the areal number density of the tips would depend on the liquid metal density, film thickness, surface tension, and work function difference. The electrostatic force between two approaching peaks is further enhanced due to the locally strengthened electric field. As a result, the electrostatic force keeps on overcoming the stabilizing surface tension and viscous force and pulling the peaks further together
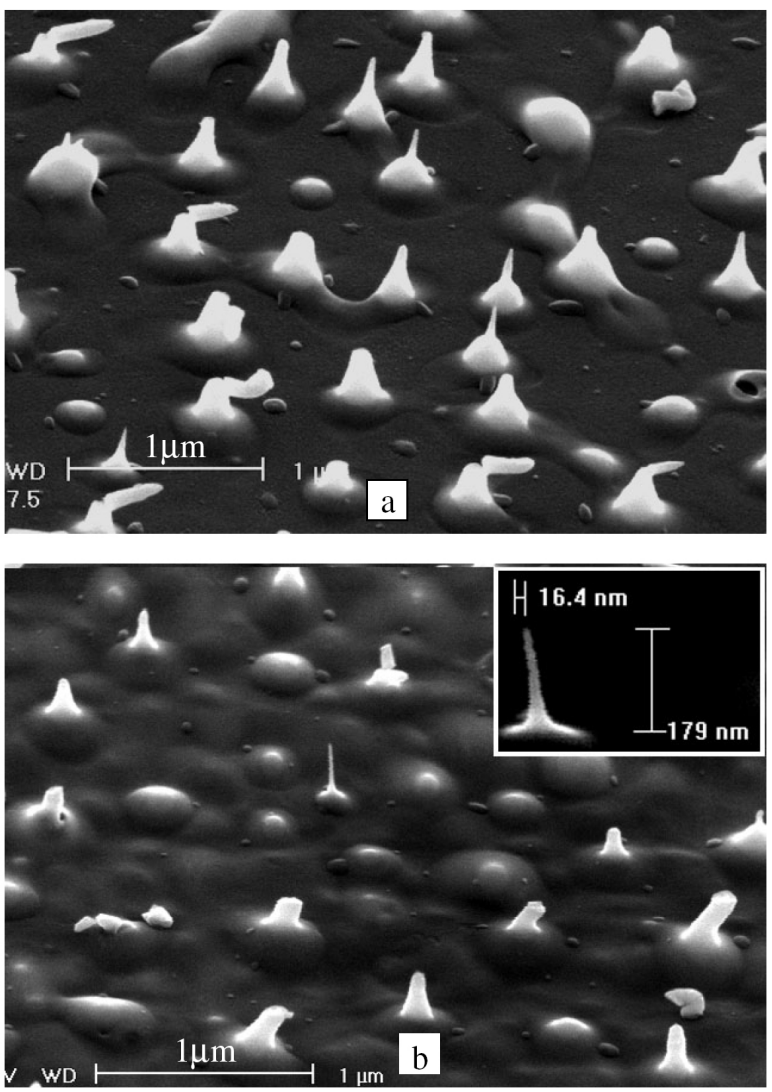

Figure 2. Laser-induced nanotip formation. (a) $\mathrm{Cr}$ tips formed on the $\mathrm{Si} / \mathrm{SiO}_{2}$ substrate; (b) $\mathrm{Cr}$ tips formed on the quartz wafer that is originally coated with $25 \mathrm{~nm} \mathrm{Cr}$. The inset is the zoom-in image of the tip at the center that has an apex of $10 \mathrm{~nm}$ and height of $180 \mathrm{~nm}$. (This tip appears tilted due to SEM stage drift during imaging.) 

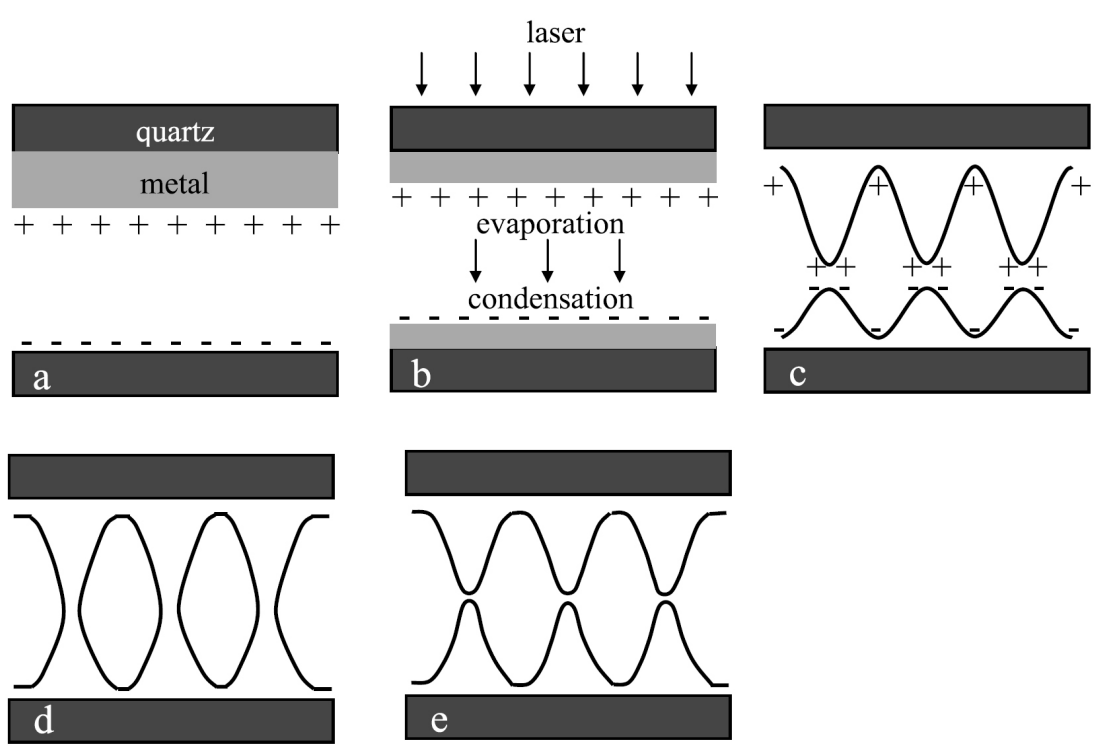

Figure 3. Schematic of the physical mechanism behind the nanotip formation. (a) Build-up of free charges on the two wafers; (b) metal transfer to the lower wafer by evaporation-condensation; (c) nanobridge formation due to attractive electrostatic force; (d) bridging of approaching peaks and charge neutralization; (e) breaking of bridges upon solidification or after separation.

until the peaks are bridged together to form a liquid bridge or the liquid metal solidifies. A similar liquid lubricant bridge formation phenomenon involving electro-hydrodynamic instability processes has been simulated for the head-disk interface system of a disk drive [30].

Once the peaks bridged together, the charges are neutralized and thus the electrostatic force disappears, and the bridges may break by the large surface tension of liquid metal that is about 20 times that of water. Meanwhile, solidification propagates from the two metal-wafer interfaces toward the gap center, because the wafers are heat sinks and the temperature distribution before solidification across the gap should be uniform (since the melting time is of order $100 \mathrm{~ns}$ which is much longer than pulse duration [16]). Nanotips are formed at the broken bridge necks before or during solidification due to surface tension and volume shrinkage, or after the two wafers were separated.

\section{Conclusion}

In summary, presented in this work is a demonstration of the use of a pulsed laser for the formation of sharp chromium nanotips. This unconventional technique uses one excimer laser pulse and the process takes only several hundred nanoseconds. Unlike other approaches for metal nanotip fabrication, the current one is capable of producing high aspect ratio metal tip arrays. The sharpest tip achieved has an apex diameter $10 \mathrm{~nm}$ and height $180 \mathrm{~nm}$. The self-formation of $\mathrm{Cr}$ pillars between the two wafers was attributed to the attractive electrostatic force caused by the work function difference of the two wafers that were in close proximity. This method could be extended to other metals, and a periodic uniform tip array could be obtained by pre-patterning the metal into identical isolated mesas.

\section{References}

[1] Jeong T et al. 2006 J. Appl. Phys. 100064308

[2] Nguyen C V, Ye Q, and Meyyappan M 2005 Meas. Sci. Technol. 162138

[3] Chen I C, Chen L H, Ye X R, Daraio C, Jin S, Orme C A, Quist A, and Lal R 2006 Appl. Phys. Lett. 88153102

[4] Tang Y, Cong H, Chen Z, and Cheng H 2005 Appl. Phys. Lett. 86233104

[5] Thomas R N, Wickstrom R A, Schrodder D K, and Nathanson H C 1974 Solid-State Electron. 17155

[6] Ding M, Sha G, and Akinwande A I 2002 IEEE Trans. Electron Devices 492333

[7] Rangelow I W and Biehl S 2001 Microelectron. Eng. 57/58 613

[8] Akiyama K, Eguchi T, An T, Fujikawa Y, Yamada-Takamura Y, Sakurai T, and Hasegawa Y 2005 Rev. Sci. Instrum. 76033705

[9] Kim P, Kim J H, Jeong M S, Ko D K, Lee J, and Jeong S 2006 Rev. Sci. Instrum. 77103706

[10] Spindt C A 1968 J. Appl. Phys. 393504

[11] Losic D, Shapter J G, Mitchell J G, and Voelcker N H 2005 Nanotechnology 162275

[12] Zou J, Wang X, Bullen D, Ryu K, Liu C, and Mirkin C A 2004 J. Micromech. Microeng. 14204

[13] Steen J A, Hayakawa J, Harada T, Lee K, Calame F, Boero G, Kulik A J, and Brugger J 2006 Nanotechnology 17 1464

[14] Liao Y S and Chen Y T 2005 J. Micromech. Microeng. 15 2433

[15] Cho K J, Ryu J T, and Lee S Y 2003 Solid-State Electron. 47 633 
[16] Chou S Y, Keimel C, and Gu J 2002 Nature 417835

[17] Xia Q, Keimel C, Ge H, Yu Z, Wu W, and Chou S Y 2003 Appl. Phys. Lett. 83417

[18] Le Drogoff B, Cui B, and Veres T 2006 Appl. Phys. Lett. 89 113103

[19] Cui B, Wu W, Keimel C, and Chou S Y 2006 Microelectron. Eng. 831547

[20] Bauerle D 2000 Laser Processing and Chemistry 3rd edition (Berlin: Springer)

[21] Allmen M and Blatter A 1995 Laser-beam Interactions with Materials-Physical Principles and Applications (Springer Series in Materials Science) 2nd edn (Berlin: Springer)

[22] Yaws C L 1998 Chemical Properties Handbook: Physical, Thermodynamics, Environmental Transport, Safety and Health Related Properties for Organic and Inorganic Chemicals (New York: McGraw-Hill)
[23] Berry R, Hall P, and Harris M 1968 Thin Film Technology (Princeton, NJ: Van Nostrand)

[24] Chou S Y and Zhuang L 1999 J. Vac. Sci. Technol. B 17 3197

[25] Chou S Y, Zhuang L, and Guo L J 1999 Appl. Phys. Lett. 751004

[26] Schaffer E, Thurn-Albrecht T, Russell T P, and Steiner U 2000 Nature 403874

[27] Pease L F and Russel W B 2002 J. Non-Newton. Fluid Mech. 102233

[28] Wu L and Chou S Y 2003 Appl. Phys. Lett. 823200

[29] Wu L and Chou S Y 2005 J. Non-Newton. Fluid Mech. 125 91

[30] Wu L 2008 J. Appl. Phys. 104, in press 